\title{
Papillomatous Erythematous Plaques of the Scrotum
}

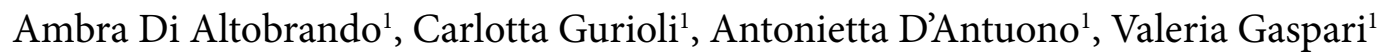

1 Dermatology, Department of Experimental, Diagnostic and Specialty Medicine, University of Bologna, Bologna, Italy

Key words: syphilis, condylomata lata, plaques, Treponema pallidum

Citation: Di Altobrando A, Gurioli C, D’Antuono A. Gaspari V. Papillomatous erythematous plaques of the scrotum. Dermatol Pract Concept. 2019;9(1):73-74. DOI: https://doi.org/10.5826/dpc.0901a18

Published: January 31, 2019

Copyright: $\odot 2019$ Di Altobrando et al. This is an open-access article distributed under the terms of the Creative Commons Attribution License, which permits unrestricted use, distribution, and reproduction in any medium, provided the original author and source are credited.

Funding: None.

Competing interests: The authors have no conflicts of interest to disclose.

Authorship: All authors have contributed significantly to this publication.

Corresponding author: Ambra Di Altobrando, MD, Dermatology Unit, Department of Experimental, Diagnostic and Specialty Medicine, University of Bologna, Via Massarenti 1, 40138 Bologna, Italy. Email: ambra.dialtobrando@gmail.com

\section{Introduction}

We describe an uncommon case of papillomatous erythematous plaques of the scrotum.

\section{Case Presentation}

A 28-year-old man presented with a 2-month history of painful growing scrotal lesions and relapsing fever. The patient was otherwise in good health. He was heterosexual and did not report any recent high-risk sexual behavior. Physical examination revealed 2 broad-based, elevated papillomatous erythematous plaques 10 and $6 \mathrm{~mm}$ in diameter, respectively, located on the front of the scrotum (Figure 1A). No other cutaneous or mucosal abnormalities were found. Dermoscopy revealed whitish papillomatous structures on a milky-red background; vessels showed a homogeneous punctiform pattern (Figure 1B). A skin biopsy and serological tests were performed. Histopathology of a 4-mm punch biopsy showed a prominent dermal infiltrate, rich in plasma cells, together with endothelial proliferation and swelling (Figure 2). Serological tests for syphilis were requested, and the Treponema pallidum enzyme immunoassay titer was positive, $T$ pal- lidum hemagglutination was reactive, and the rapid plasma reagin titer was 1:64. Human immunodeficiency virus (HIV), hepatitis $\mathrm{C}$ virus, and hepatitis $\mathrm{B}$ virus serology results were negative. A diagnosis of secondary syphilis was made, and scrotal lesions were diagnosed as condylomata lata. Lesions and symptoms completely resolved with a single dose of 2.4 million units IM of penicillin G benzathine.

\section{Conclusions}

Due to their friable consistency, condylomata lata represent an infectious form of secondary syphilis, a systemic venereal disease caused by $T$ pallidum that can involve most organs and tissues of the human body and have several clinical stages (primary, secondary, early latent, late latent, and tertiary). After a decline in the late 20th century, a new wave of syphilis has been reported over the last 2 decades, especially among men who have sex with men and patients with HIV. Primary syphilis is often overlooked because of its quick course and poor symptomatology; therefore, many patients come to clinical consultation when they show mucocutaneous involvement in the secondary stage of the disease, 6-8 weeks after inoculation of T pallidum [1,2]. 
Skin lesions of secondary syphilis can take many mucocutaneous forms, including condylomata lata, but also macular, papular, follicular, lichenoid, psoriasiform, pustular, Sweet syndrome-like, and annular aspects, thus justifying the label "the great imitator." Besides skin lesions, systemic symptoms such as fever, headache, malaise, and lymphadenopathy are common in secondary syphilis [2]. However, the absence of pathognomonic features and the increasing unusual manifestations often determine a delay in diagnosis and treatment.

In our case, the clinical presentation could be suggestive of condylomata lata, even if the patient's history was quite misleading. Aside from the protean clinical manifestations, the histopathological features of condylomata lata are also polymorphic and aspecific, representing a diagnostic challenge for the dermatopathologist. The most frequent histological patterns show hyperkeratotic, psoriasiform, or ulcerated aspects. The dermis generally shows a perivascular and periadnexal infiltrate, rich in plasma cells [1,2].

Dermoscopy may turn out to be very useful in order to exclude differential diagnoses, especially neoplastic ones. Differential diagnoses include squamous cell carcinoma, basocellular carcinoma, genital warts, eruptive xanthomas, papular granuloma annulare, lymphoma, leukemia, leprosy, sarcoidosis, psoriasis, and cutaneous tuberculosis [2]. Moreover, the observation of papillomatous structures and homogenous dotted vessels on dermoscopy can suggest to the clinician an infectious origin and support further inves-
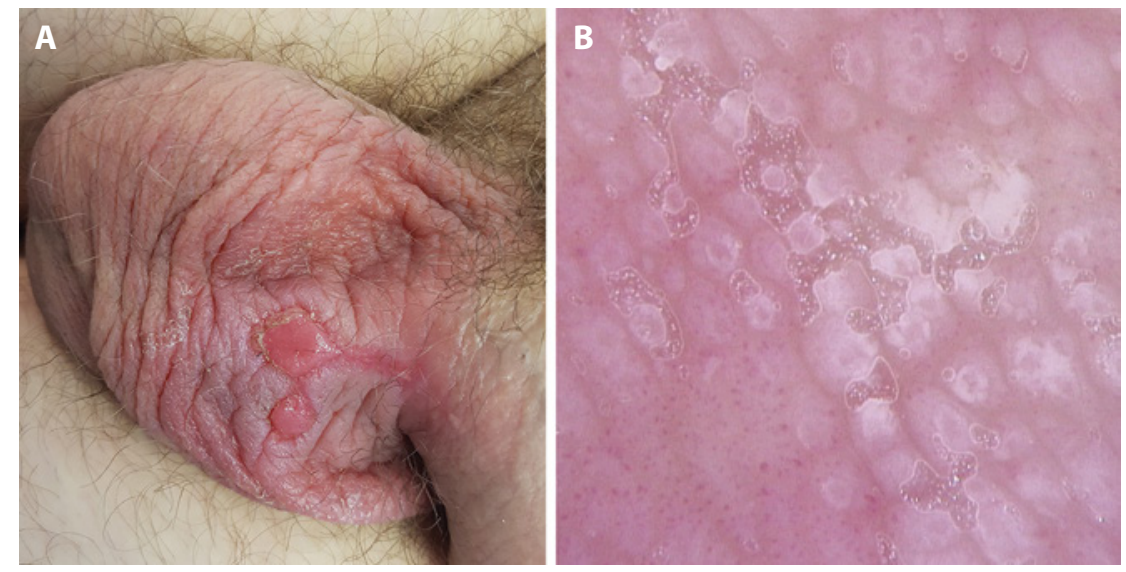

Figure 1. (A) Broad-base infiltrated papillomatous, erythematous plaques measuring 10 and $6 \mathrm{~mm}$ in diameter, respectively, on the front of the scrotum. (B) Whitish papillomatous structures on a milky-red background; dotted vessels represent the main vascular pattern. [Copyright: (C2019 Di Altobrando et al.]

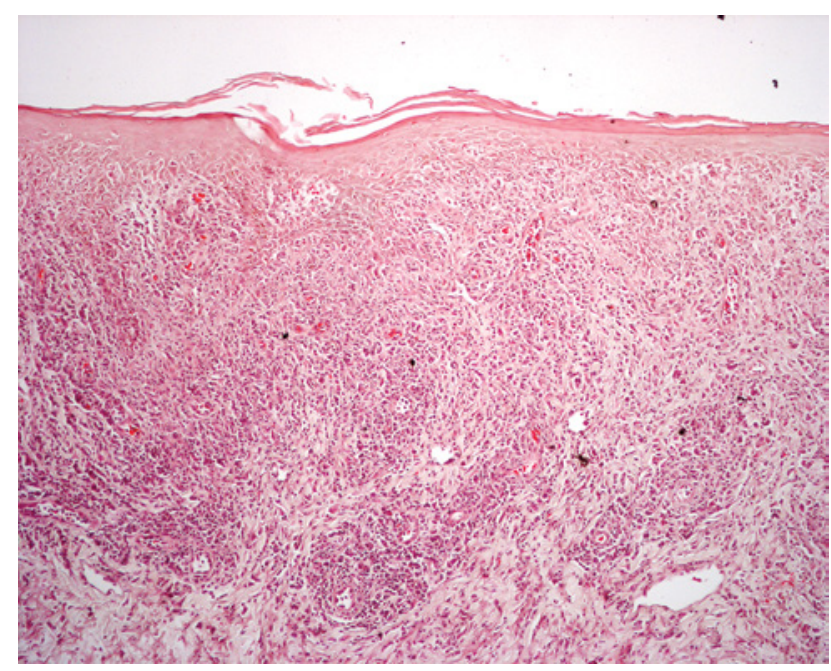

Figure 2. A prominent dermal infiltrate rich in plasma cells together with endothelial proliferation and swelling. [Copyright: C2019 Di Altobrando et al.]

tigations, including serological tests for syphilis. However, the absence of dermoscopic pathognomonic features and increasing unusual clinical manifestations justify the frequent missed and delayed diagnosis of condylomata lata and of secondary syphilis.

In conclusion, a high level of suspicion is necessary to achieve early diagnosis and therapy and prevent further progression.

\section{References}

1. Afra TP, Handa S, Razmi TM, Vinay K. Secondary syphilis: lest we forget it. Postgrad Med J. 2018;94(1113):415.

2. Rysgaard C, Alexander E, Swick BL. Nodular secondary syphilis with associated granulomatous inflammation: case report and literature review. J Cutan Pathol. 2014;41(4):370-379. 